\title{
THE ART OF LISTENING*
}

\author{
DOMINICK A. BARBARA \\ New York City \\ In listening mood she seemed to stand, \\ The guardian naiad of the strand - \\ Sir Walter Scott
}

Listening is an art. To be well performed, it requires more than just letting sound waves enter passively into ears. Good listening is an alive process demanding alert and active participation.

If listening is an art, then it requires knowledge and effort. It is in essence a mental skill that can be developed primarily through training and practice. If we are to learn to know how to listen well, we must proceed as we would in learning any other art such as music, painting, architecture or acting. That is, if we are to become good listeners, we must first attempt to inquire about all the basic essentials of productive listening, and second, we must do a great deal of practicing until we can master its workings.

The art of listening is not something we can acquire through "do-it-yourself" shortcuts. It requires constant practicing and thinking. The good listener, as Nichols and Stevens so aptly put it, "listens between the lines. He constantly applies his spare thinking to what is being said." 1 The good listener, while he is attentive to what is being said, is also aware of the total facts at hand, with both their verbal connotations and their nonverbal implications.

First of all, the practice of an art requires discipline. It is essential, according to Fromm, "that discipline should not be practiced like a rule imposed on oneself from the outside, but that it becomes an expression of one's own will; that it is felt as pleasant, and that one slowly accustoms oneself to a kind of behavior which one would eventually miss, if one stopped practicing it." 2 In desiring to be good listeners, it is imperative that we "be in the mood" to want to listen and at the same time consider some of its more challenging aspects. We might even set aside certain times of our daily life for serious listening, in contrast to the vast amount of superficial listening that goes on when we chit-chat about the weather, talk about social doings or ramble on during a coffee break.

Concentration is a second prerequisite of good listening. So many of us in our Western Culture have difficulty in concentrating. We take a peculiar pride in doing many things at once, such as watching television, reading a book, talking, smoking, eating and drinking. This lack of concentration is also prevalent among us because of our fear of being alone with ourselves. To sit still, to be silent and to concentrate on something specific for any length of time is impossible for most people. They become nervous and fidgety and, to

* Abstracted in part from the author's book: The Ant Of Listening published by Charles C. Thomas, Springfield, Illinois. 
allay their anxieties, run to almost any form of hectic or compulsive activity.

In order to concentrate fully when listening, we should be patient with ourselves. This for modern man is as difficult as discipline and concentration. In this age of speed reinforced by the use of the airplane, telephone, radio and television, modern man is trained to think that he loses time should he pause to concentrate. He feels compelled to listen to only those facts which he can quickly digest and keep at his funger tips with as little effort or concentration as possible. To linger on and reflect about a certain situation or fact goes against his idealized concept of himself as "a man of action."

In learning concentration, it is most important that we remove distractions in the path of our listening. We can then be alone with our innermost feelings and thoughts and can give to ourselves and our surroundings the fullest of our interest and attention. With deep concentration we can keep our ears fully opened to all aural stimuli and, at the same time, be curious and alert enough to tune in to our proper wave lengths. We can then listen without too much confusion, apprehension or mental interference.

To concentrate and be interested while listening, it is essential that we give our full attention to the situation at hand. That means living fully in the present, in the here and now, and evaluating things as they are and not as they should be. It also means less trivial talk and more serious exchange of ideas, feelings and opinions. Finally, it entails being sensitive to oneself and to other pcople's wishes, thoughts and beliefs.

Good listening demands active participation. It involves keeping one's mind in a state of relaxed alertness, open and flexible to all relevant changes in a given situation. To listen with an active and open mind also entails giving a speaker a chance to present all the facts involved and not jumping to premature conclusions. The effectual listener is constantly on the alert to find something interesting in what is being said and attempts to keep the discussion moving and alive, by either asking productive questions or adding something constructive to the situation as a whole. The ineffectual listener, on the other hand, is on the defensive, planning a rebuttal, scheming questions designed to embarrass or belittle the speaker or using his attack to further only his own selfish motives.

The productive listener develops his listening skill to the degree that he can direct his full attention to central ideas. He learns to utilize this ability constructively by focusing his energies toward the basic meaning or theme of a situation, instead of getting lost in remembering every fact as it is presented. He is also less impressed by the persuasive power of the "spoken word," or the superficialities of the speaker, and more concerned with getting to the "heart of the matter."

A third factor contributing to the effectiveness of listening is that of comprehension to understand and grasp the true idea or meaning of that which is heard. The facts one hears and the principles that are deduced from what is being said or implied lead in turn to levels of agreement between the listener and the speaker on the fact or idea which is being discussed - then effective listening has been achieved.

Comprehension in any given situation is to be found, not in the words that are spoken, but in the meaning given by both the sender and the receiver. Both the speaker and the listener, if properly attuned to each other, can break the initial screen of intellectualization 
and arrive at true meaning and understanding. If effective communication occurs, then both partiesinvolved can leave the situation feeling sarisfied and all the wiser.

Comprehension in listening is often difficult because we think faster than we talk. The rate of speech of most Americans is, as was previously mentioned, about 125 words a minute, but we think four times that fast. Thus, as we can see, there is a lot of time left for spare thinking. It is what we do with this extra time that makes us either good or poor listeners. If we are poor listeners, as Nichols and Stevens explain it, "we soon become impatient; our thoughts turn to something else for a moment, then dart back to the speaker. These brief side excursions continue until our mind tarries too long on some other subject. Then, when our thoughts return to the person talking, we find he's far ahead of us. Now it's harder to follow him and increasingly easy to take off on our side excursions. Finally we give up; the person is still talking, but our mind is in another world." 3

The good listener in contrast is selective and uses his spare thinking time to advantage by asking himself what is being said, in what context is it being said and are the speaker's facts accurate. He also tries to be as much alone with his thoughts and feelings as possible so that he can concentrate and listen with little prejudice, condemnation or criticism. $\mathrm{He}$ finally makes efforts to reach beyond the actual words that are spoken and get at the basic meaning by visualizing the situation as a whole. To comprehend fully, it is essential that one sharpen his listening skill to the point where he is interested in what he is listening to and, at the same time, avoids being easily distracted.

Comprehension is considered, in the main, as the ability to recall immediately, or at a later time, a sampling of what has been read or heard. Rarely does it take into account what the individual does with the retained material, nor does it emphasize the critical and creative evaluation of what is received. In our schools and colleges, for instance, such a definition of comprehension, according to Johnson, "does not encourage one to develop the implications of the message nor to extend and refine it. It encourages the student to listen the way a tape recorder 'listens' - and consequently to speak the way a tape recorder 'speaks.' It is as though the instructor were to talk 'into his students' on Mondays and Wednesdays and to 'play them back' in a quiz on Friday." 4

As human beings, we may desire to hear only what we want to hear and to discard anything else we do not want to hear. This interferes with good listening. To remedy this situation, we must try to see less of the world from within ourselves and attempt to be more objective. This can be accomplished by improving our faculty to see people and things as they are, and not as they should be. We can thus separate this objective picture from a picture which is formed by our own inner illusions, anxieties and fears.

To acquire this capacity for objectivity when listening, we must "hear the other person out" without imposing our preconceived notions or opinions. This requires reason, humility and a degree of self-control. While listening, the main object is to comprehend most of what the speaker is saying, holding back judgments and decisions until after he has finished. Only then can we objectively and honestly reach a true evaluation of what was said. Having listened to our fullest capacity, we can now, with "open ears," summarize, digest and evaluate within ourselves what is of importance to us and to the situation 
as a whole. A realistic self-evaluation achieved, agreement occurs between speaker and listener, and true communication takes place.

To listen and to think actively one must have an alert, active mind, with plenty of native curiosity sustained by many interests. One's zest is an emotional source or fuel, from which the thinking mind will go and grow. A person who grows in a stimulating atmosphere of intellectual interests will want to seek more and more information to foster his further growth. He will develop the habit of concentrating and actively applying his listening skill to its fullest capacity. He will also want to listen more and better, so that he can comprehend and understand more effectively the world about him. As he more fully understands surroundings, he accordingly strives toward a clearer and deeper experiencing of himself. Ultimately, as Karen Horney succinctly states, he "strives toward a greater ability to tap his resources and to use them for constructive ends; toward a clear perception of his direction in life, with the assumption of responsibility for himself and his decisions...." 5

\section{Communicative Aspects of Good Listening}

In a recent article, "The Integrity of the Listener," Richard Henry considers successful communication as a function, not only of agreement on the meaning of words or phrases, but also the taking into account of the fact that there are patterns of thought and meaning that condition one's reactions to the statements of others. Good communication thus results in understanding that the same words mean different things to different people, depcnding upon their experience and their patterns of thought and conceptions. Words - one might say - have little or no intrinsic meaning; their meaning is largely determined by the context in which they appear. And that context "is at least a two-dimensional one: the context of the speaker, and the context of the listener, -- each of them slightly different." 6

When listening we have to consider the nuances of meaning of different languages, the specific context within which words are used to convey meaning and the emotional tone of the speaker and the attitudes this tone conveys. For instance, often when disagreement occurs and communication breaks down between two people, it is important to look, not just at the disagreenent itself, but also at the mood in which it is expressed. If you express a point of view or an assertion to someone else and his expressed disagreement conveys back to you the impression that he considers you ignorant or misled, communication has failed. In other words, when listening with "arrogance or prejudice," we distort the true intent of the message, by misleading our speaker with our self-imposed attitudes.

To listen effectiveiy, verbal affirmation of our feelings or attitudes is not enough. For understanding to result there must be sincere effort expended on the part of the listener. He must be patient, open minded and to some degree enter genuinely into the emotional life of the speaker. To make this point, Harry Stack Sullivan once said: "In dealing with students, with patients, or with any group or nation the first step is to see the world through their eyes, to enter into what they are trying to do, however strange their behavior seems. 
Genuine communication is impossible on any other basis."

For communication to be effective, its network has to be functionaliy organized and the flow of messages has to be adapted to the capacity of both the speaker and the listener. Information which flows from one person to another is said to have content when sender and receiver can reach levels of agreement regarding the statement or subject matter at hand. It further entails the use of this information for knowledge which enables one to reconstruct past events, to predict future events and hence to engage in successful action.

Correct evaluation of the past and appropriate decisions for the future are largely based upon the relevance, accuracy and completeness of information. ${ }^{7}$ In this particular aspect of communication, listening plays a most important role. For, to evaluate efficiently what someone else is attempting to convey, we must take into account not only what we hear from the outside, but whatever additional information comes to us simultaneously from our inner wishes, feelings and beliefs. It is in the appropriate handling of both this outside perspective and messages from our inner sources that we can effectively arrive at a correct evaluation of the information.

The efficiency of a communication system depends to a large extent upon the feedback circuits and the use to which they are put. ${ }^{7}$ For example, if, when listening to a particular speaker, the effect of his message upon us is so received that it provokes disagreement, or little response at all, then soniething is defective in the communication system. For people to relate to each other, it is essential that they favorably influence each other. When we cease to listen effectively, or do not relay favorable influences back to others, our relationships are disturbed - we stop learning, do not bring information up to date and feed-back faulty messages to others. All of these disturbances in the feedback mechanism tend to cause a gradual breakdown in the communication system.

Successful communication also depends upon the cooperation of at least two or more people. In this context, the listener also plays a specific role. His attitude, when listening effectively to others, is one of curiosity and eagerness to find out what the effects of a statement or an action might have been. He makes efforts at the same time to consider other individuals and groups in terns of whether or not they will be able to cope with the effects of a projected statement or an anticipated action. ${ }^{7}$ A good listener works incessantly toward facilitating and improving the feedback mechanism. He attempts to visualize situations as a whole and keeps alive the communicative process by asking others for suggestions and incorporating these in his future actions.

A listener, sincere in his desire to facilitate the efficiency of communication with others, is highly selective and times his responses so that his receivers are capable of perceiving and interpreting them without undue difficulty or haste. He is alert to necessary corrections in the information from others or from within hinself for clarity, distinctness and relevance. Finally, in his evaluations, he is less interested in the "why" or "what" of a message than he is in the "how" of communication. This latter inquiry leads to better discussion and understanding and thus to heal thier relationships.

In listening with purpose, responsibility must be shared by both the speaker and the listener. Both have the same problem of keeping the communicative process alive. Each 
must also enlighten his own self-interest to the degree that he can facilitate communication with others, by making good use of circuit response. In this way the listener's reactions help the speaker and make it easier for him to bring out what he wishes to convey and, in the last analysis, to improve total communication.

In effective communication, the language used must be clear, concise, simple and flexible in nature. In relating to others, we express our opinions, feelings, beliefs or awareness to the degree to which our thoughts or statements are projective representations of our inner state at the particular time of expression. For a language therefore to be meaningful, it must in itself be variable, flexible and in dynamic change from person to person and situation to situation, while having clarity for both speaker and listener.

In order to become better listeners, and to give our lives a constructive and purposeful meaning, it is essential that we talk simply and understand clearly. Since speech is the essential means of communication, mutual understanding must depend upon shared meanings. Meaning is relative to experience and, for a message to be understood, there must be an overlapping of experience between sender and receiver. Also, the cultivation of a productive language will enable us to listen to and understand the implied meanings behind words, names and labels. As we gain a better knowledge of the structure of the world we live in, its complexities will grow less mysterious and confused and finally, as we communicate with each other with truthful meaning, a sense of responsibility, mutual rapport and understanding will develop and grow.

\section{The Listener as an INDividual}

Man is a communicating animal, and so much of what he achieves of an understanding of others depends upon the degree to which he can verbalize his thoughts, wishes and feelings. On the other hand, real communication or relatedness between people becones difficult, if there is present a lack of desire for genuine communion or concern for others as individuals. Henry says the aim of real communication "is a kind of communion with the other person, a sharing of one's self and an appreciation for the other which affirms the integrity of each. Real understanding comes, we might say, where there's an unspoken agreement that each recognizes the right to self-hood of the other, a self-hood which is unique, and accepted and rejoiced in as such, - and further, which eagerly desires the other more fully and dceply than he does before the process of communication begins." 7

The mere acceptance of others is just the beginning of communication. There must be a full acceptance of the other person, a communion with him as he is, and a relinquishing of the image of this same person that you may have created in your own mind. Only when we can relate to others with real understanding and genuine feelings can effective communication take place.

To see others as they actually are, and not as we picture them to be, is for the most part extremely difficult. For, as Williani James once said, "Most of us grow more and more enslaved to the stock conceptions with which we have once beconie faniliar, and less and less capable of assimilating impressions in any but old ways." We are creatures of habit. We are so subjected to past experience and to pulls from emotional forces within 
ourselves that we see or hear only what we want to, and in terms of our individual beliefs, thoughts or desires. We tend to create images of others by the things they say or do over the period of our acquaintance with them. We make all sorts of inferences about what others do by their social standing, jobs, religion or family background.

With long acquaintance, we tend to arrive at the point of predicting and anticipating the other person's reactions to such-and-such a problem or situation, and make guesses about what he will think or do or say under certain conditions. Finally, we systematize our thinking and listening to the point that we make ourselves believe that "we can expect this or that person to react in any way but the way he's behaved in the past under similar conditions." We create, to quote from Henry, "images which are a figment of our own imaginations, which cast others in a mold of the person-we-wish-they-were, but which does violence to the selves they really are." 6

Communication can become more effective as we see and listen to others as they realistically appear, rather than the person we wish they were, or have decided in terms of past impressions they should always be. In summarizing at this point, it is essential to see others as unique personalities, with beliefs, thoughts and wishes of their own, and whose capacities for thinking and experiencing are constantly changing, growing, developing into something new and stimulating. Genuine understanding is dependent, above all else, on this eagerness to affirm the integrity of others. 6

In productive listening, it is essential that we not place screens or facades in the way of our arriving at the truth of the matter. In The Brothers Karamazov, Dostoyevsky wrote: "... The man who lies to himself and listens to his own lies comes to such a pass that he cannot distinguish the truth within him, or around him, and so loses all respect for himself and for others...."

When listening to others, we must listen with open ears not only to the words or facts expressed, but attempt to strive toward mutual communication and mutual understanding. In a real conversation we no longer know who talks or who listens. We become lost in the total communicative atmosphere, as we relax, come closest to our feelings and arrive at free verbal intercourse. Productivity reaches its highest peak, our listening becomes highly selective and we become more aware and attuned to the essence of the facts or situation at hand. We reach mutual levels of agreement, favorably influence each other, learn from the communication situation and leave it wiser and healthier.

Inherent in man, according to Horney, "are evolutionary constructive forces, which urge him to realize his given potentialities... It means that man, by his very nature and of his own accord, strives toward self-realization, and that his set of values evolve from such striving. Apparently he cannot, for example, develop his full human potentialities unless he is truthful to himself; unless he is active and productive; unless he relates to himself and to others in the spirit of mutuality."8

In listening with meaning, we must constantly seek to arrive at an ever increasing awareness and understanding of ourselves and others. In this sense, self-knowledge can become not an aim in itself, but a means of liberating the forces of spontaneous growth. To grow we have to assume responsibility for ourselves. We can, in this sense, accept 
working at ourselves not as a prime moral obligation, but a moral privilege. ${ }^{8}$ The more we take our growth seriously, the more we will develop the desire to do so. And the more we get rid of our own neurotic shackles, the freer we will become to grow within ourselves, and to free ourselves to love and to have concern for others. Thus we can have rational faith, as Fromm sees it, as "a conviction which is rooted in one's own experience of thought or feeling."9 It will have the quality of certainty and firmness of our convictions and will pervade the whole personality, rather than a specific belief.

For listening to be effective as an art, we must be active participants in its whole process. This means not only "doing something" with our ears, but responding holistically — both with our hearing capacity and our inner perceptions. It also entails being fully attentive and awake, alert at every minute to screen out inner prejudices, condemnations or preconceived notions. It further encompasses being active in thought and feeling, with one's eyes and ears, to avoid inner inertia, and to be open and receptive to others. The capacity to listen demands a state of zest, enhanced vitality, aliveness and the firm desire to commune with others. With all this in hand, we can now grow healthily as human beings, tend to influence others with meaning and arrive at mutual and truthful communication.

\section{REFERENCES}

1. Ralph G. Nichols \& Leonard A. Stevens Are You Listening? New York: McCraw-Hill, 1957, p. 83.

2. Erich Fromm The Art of Loving. New York: Harper \& Bros., 1956, p. 111.

3. Ralph G. Nichols \& Leonard A. Stevens, ibid., p. 151.

4. Wendell Johnson, ibid., p. 195.
5. Karen Horney, Neurosis and Human Growth. New York: Norton \& Company, 1950, p. 364.

6. Richard Henry, "The Integrity of the Listener," Today's Speech, Sept. 1957, Vol. 5, No. 3.

7. Jurgen Ruesch, ibid., p. 178, 35.

8. Karen Horney, ibid., p. 15.

9. Erich Fromm, ibid., p. 121.

MS. received Oct. 1,60 .

\section{NECROLOGY}

KrisPal Singh Sodhi Professor of Psychology at the Free University of Berlin. b. 15 Aprill 1911 at Rorkee, India. d. 3 May 1961 in Berlin, Germany.

I wish to express my deep condolence to the so early death of Prof. Sodhi. I first met him at the Psychological Institute of Free University of Berlin in the summer of 1956. Prof. Oswald Kroh was already dead, and he was taking charge of the Institute as a Dozent. He told me that he studied also under Prof. Köhler and Prof. Wertheimer. Last summer $I$ met him again at the International Congress of Psy- chology in Bonn. He had been promoted to the Professor of Psychology at the Free University, which would be a great honor, esp. as a foreign psychologist. In my second world tour I got deep impression on the international activities of Indian psychologists, such as Drs. Bagchi, Bindra, Sodhi, et al. It is a great regret esp. for us Asian psychologists that we lost a distinguished scholar from Asia as Dr. Sodhi.

$$
\text { Kyoto University Koji Sato }
$$

